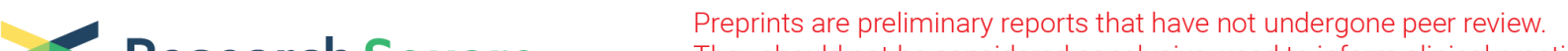 s.mase \\ First Report of Rickettsia Asembonensis in Small Ruminants
}

\author{
Van Lun Low \\ Universiti Malaya \\ Siti Sarah Azhar \\ Universiti Malaya
}

Tiong Kai Tan ( $\square$ tantk@um.edu.my )

Universiti Malaya https://orcid.org/0000-0003-0297-1727

\section{Premaalatha Bathmanaban}

Kementerian Pertanian dan Industri Asas Tani Malaysia

\section{Sazaly AbuBakar}

Universiti Malaya

\section{Panchadcharam Chandrawathani}

Ministry of Agriculture and Land: Kementerian Pertanian dan Industri Asas Tani Malaysia Hassan Nizam Quaza Nizamuddin

Ministry of Agriculture and Land: Kementerian Pertanian dan Industri Asas Tani Malaysia

\section{Mohd Saeid Faizah Hanim}

Kementerian Pertanian dan Industri Asas Tani Malaysia

\section{Ngah Hamid Akma}

Kementerian Pertanian dan Industri Asas Tani Malaysia

\section{Mohd Noor Norlizan}

Kementerian Pertanian dan Industri Asas Tani Malaysia

\section{Yvonne Ai Lian Lim}

University of Malaya: Universiti Malaya

\section{Short Report}

Keywords: infectious diseases, Rickettsial, zoonotic pathogens, Malaysia

Posted Date: January 3rd, 2022

DOI: https://doi.org/10.21203/rs.3.rs-1213907/v1

License: (c) (1) This work is licensed under a Creative Commons Attribution 4.0 International License. Read Full License 
Version of Record: A version of this preprint was published at Veterinary Research Communications on February 22nd, 2022. See the published version at https://doi.org/10.1007/s11259-022-09904-9. 


\section{Abstract}

Rickettsioses is an emerging infectious disease in Southeast Asia caused by different organisms in the Rickettsiae bacterial tribe, a gram-negative obligate intracellular bacterium. There is limited information regarding the vertebrate hosts of Rickettsia spp. This study aims to detect and identify Rickettsia agents present in wildlife and domesticated animals in Malaysia using Polymerase Chain Reaction (PCR) and sequencing approach with phylogenetic analysis. Rickettsia sp. was detected in $2(0.67 \%)$ of 300 animal blood samples. The positive samples were derived from a goat $(5.56 \%$ of 18$)$ and a sheep $(2.22 \%$ of 45$)$. Based on the analysis of the Rickettsia citrate synthase gene $(g / t A)$, both sequences demonstrated 99.64\% sequence similarity to Rickettsia asembonensis, a species that is known to infect humans and macaques. This study reported for the first time the detection of $R$. asembonensis in sheep and goats in Malaysian farms, suggesting this species may be adapting in a wider range of animals, specifically farm animals, therefore, poses a zoonotic threat to the local populace particularly to the farm workers or animal handlers. The low infection rate of this pathogen yet is of public health importance highlighted the needs of continuous surveillance of emerging and reemerging pathogens among animal reservoirs.

\section{Introduction}

Rickettsioses is a neglected infectious disease in Southeast Asia despite being one of the leading causes of treatable unrecognized febrile illnesses. Notably, Rickettsia typhi and some members of spotted fever group Rickettsia, exemplify important species that causes human disease among the local population (Aung et al., 2014). One of the hallmarks of Rickettsia is their ability to adapt to a wide variety of hosts (Weinert et al., 2009). Rickettsia is maintained in nature in a continuous cycle between infected arthropods, and one or several of host animals. Hence, the possibility of other animals as reservoirs of these emerging pathogens has gained the attention of researchers worldwide. Several studies across Southeast Asia have reported rickettsial infections in animals such as wild rodents, dogs, monkeys and a range of hematophagous arthropods (Low et al., 2020).

Essentially, human infections reported in Southeast Asia were frequently associated with animal interactions (Edouard et al., 2014; Kho et al., 2017). It is important to establish reservoir hosts that may participate in the enzootic maintenance of Rickettsia as it allows researchers and local authorities to identify risk and target control measures especially to animal handlers, farm workers and agricultural workers who are at higher risk of developing these tick and flea-borne diseases. Accordingly, this study aimed to detect and genotype Rickettsia DNA from various blood samples of wildlife and domesticated animals in Malaysia.

\section{Materials And Methods}

Archived blood samples of wildlife and domesticated animals which were provided by the Veterinary Research Institute (VRI), Department of Veterinary Services, Malaysia were stored at $-20^{\circ} \mathrm{C}$ prior to extraction. DNA extraction was performed on a total of 300 animal whole blood samples (55 deer, 73 
cattle, 18 goat, 45 sheep, 69 equine, 5 orangutan, 1 simian, 2 tapir, 1 otter, 6 tiger, 1 fox, 12 rabbit, 1 binturong, 6 sun bears, and 5 elephant). Genomic DNA was extracted from $200 \mu$ l of each blood sample according to the protocol of the QIAamp DNA Mini Kit (QIAGEN Inc.,Valencia, CA). DNA was eluted in 50 $\mu$ I of elution buffer and samples were stored at $-20^{\circ} \mathrm{C}$.

Rickettsia DNA detection was performed using conventional polymerase chain reaction (PCR) with primers CS-239 (5'-GCT CTT CTC ATC CTA TGG CTA TTA T -3') and CS-1069 (5'- CAG GGT CTT CGT GCA TTT CTT $-3^{\prime}$ ), targeting an $₫ 800$-bp fragment of the citrate synthase gene ( $\left.g / t A\right)$ (Labruna et al., 2004). All reactions were performed in a final volume of $25 \mu$ involving 25-50 ng of genomic DNA, $12.5 \mu$ l of MyTaq Red Mix (Bioline Reagents Ltd., London, UK) and 10 pmol of each forward and reverse primer using the Applied Biosystems Veriti 96-Well Thermal Cycler (Applied Biosystems, Inc., Foster City, CA). For each set of reactions, a positive control and a negative control was included. The final thermal-cycling conditions were set to an initial denaturation at $95^{\circ} \mathrm{C}$ for 3 mins followed by 40 cycles of denaturing at $95^{\circ} \mathrm{C}$ for $20 \mathrm{~s}$, annealing at $52{ }^{\circ} \mathrm{C}$ for $20 \mathrm{~s}$, extension at $72{ }^{\circ} \mathrm{C}$ for $40 \mathrm{~s}$, and a final extension at $72{ }^{\circ} \mathrm{C}$ for 5 mins. The PCR products were visualized in a $2 \%$ agarose gel. Positive amplicons were then sent to a local company for bi-directional sequencing using both forward and reverse primers.

Sequences generated from the present study were deposited into the GenBank database under accession numbers OL502704-OL502705. Sequences were subjected to Basic Local Alignment Search Tool (BLAST) analysis (https://blast.ncbi.nlm.nih.gov/Blast.cgi) to identify homologous sequences. The sequences were trimmed and aligned using the BioEdit Sequence Alignment Editor Software (Hall, 1999). A dendrogram was constructed to determine the phylogenetic position of Rickettsia identified in this study using the neighbour-joining method with the MEGA X software (Kumar et al., 2018). The NJ bootstrap values were evaluated using 1000 replicates with Kimura's two-parameter model of substitution (K2P distance). Rickettsia typhi (U59714) was used as an outgroup.

\section{Results And Discussion}

Of 300 animal blood samples provided by the diagnostic lab, two samples were successfully amplified based on the gltA gene of Rickettsia with an overall infection rate of $0.67 \%(2 / 300)$. The positive samples were derived from a goat with an infection rate of 5.56\% (1/18) and a sheep with an infection rate of $2.22 \%(1 / 45)$. None of the blood samples of wildlife animals reported rickettsial infections. The goat and sheep sample originated from a private and government farm, respectively. Our records state that the goat sample was sent for a diagnostic test as it presented symptoms such as lack of appetite, paleness, and weight loss while the sheep sample was sent for routine screening.

Through BLAST analysis, the sequence obtained from the goat (G325) and sheep (S102) both demonstrated $99.64 \%$ sequence similarity to Rickettsia asembonensis (MK923743), a recently discovered isolate from the ectoparasites of domestic animals in Peru, distinct from the original Kenya strain (Maina et al., 2016). The neighbour joining dendrogram constructed based on the $g / t A$ gene sequence in Fig. 1 revealed that both sequences $\mathrm{G} 325$ and S102, clustered with the respective reference $R$. asembonensis 
sequences (KY445724, KY445725, KX196267, AF516333) retrieved from the NCBI GenBank and showed a close relationship with $R$. senegelensis thus, confirming the findings obtained from the BLAST analysis. We reported the first detection of a genotype of Rickettsia asembonensis in sheep and goat in Malaysian farms.

Rickettsia asembonensis is a newly identified species (Maina et al., 2016), closely related to $R$. felis, and together with $C a$. $R$. senegalensis and other genetically related species grouped as $R$. felis-like organisms (RFLO). There have been several reports of partially characterized agents that were closely related to $R$. asembonensis prior to its first complete characterization including the Rickettsia sp. RF2125, which was first identified in the flea specimens along the Thai-Myanmar border (Parola et al., 2003). Reports of Rickettsia asembonensis and those genetically related, have been identified in various flea species (predominantly Ctenocephalides felis) collected from domestic animals across the world (Maina, et al., 2016). In Malaysia, Rickettsia sp. Rf31, a strain of $R$. senegalensis and Rickettsia sp. RF2125, a strain of $R$. asembonensis have been reported in fleas (Ctenocephalides felis and Ctenocephalides orientis) and tick (Rhipicephalus sanguineus) parasitizing dogs and cats in several studies (Low et al., 2017; Mokhtar \& Tay, 2011; Tay et al., 2014). In a vector surveillance study among farm animals and peri-domesticated animals in rural villages of Peninsular Malaysia, Rickettsia sp. RF2125 was detected in ticks (predominantly Haemaphysalis spp.) parasitizing cattle and the peri-domesticated animals (Kho et al., 2017). As a result, the potential of ectoparasites of domestic animals as vectors of this emerging pathogen should not be disregarded.

Despite the extensive research on the ectoparasite vectors of $R$. asembonensis, there is limited study on its animal reservoirs. Thusfar, it has been detected in the blood sample of healthy cynomolgus monkeys in Malaysia (Tay et al., 2015) and in blood samples of cats in Thailand (Phoosangwalthong et al., 2018). The identification of $R$. asembonensis in a goat and a sheep in this study therefore suggests that the infection caused by this species may be present in a wider range of animals, specifically farm animals.

The absence of rickettsial infections in other domestic animals such as cattle, may be due to better tick control or compliance to the Herd Health Program in the farms (Rohaya et al., 2017; Tay et al., 2014). Their compliance to these programmes encourages the implementation of additional control measures to avoid any disease-causing factors, such as eliminating potential vectors. Admittedly, these samples were sent to the diagnostic lab on account of suspicion of a parasitical infection, implying that these samples may not be a good representation of the population for a bacterial study. The PCR assays in this study were based on the gltA gene fragment of Rickettsia spp. as it is well-conserved, and a more extensive reference sequences are available in the NCBI GenBank for phylogenetic analysis. A gltA gene amplicon provides conclusive evidence that the agent belongs to the genus, Rickettsia (Parola et al., 2005). However, previous studies have used gltA PCR assay for initial screening of Rickettsia DNA before amplifying other Rickettsia specific genes such as ompA and ompB gene fragment (Kho et al., 2017). Since the detection was solely by glt $A$ gene amplification, it is possible that it has remained undetected in most of the blood samples. 
Our findings pinpoint the need of continuous surveillance of emerging and reemerging pathogens in animal reservoirs. Although low infection rate of $R$. asembonensis was detected in sheep and goat samples in this study, its zoonotic potential should not be disregarded in view of the close contact of animal farm workers or handlers with the animals. However, human pathogenesis of $R$. asembonensis remains unclear. There is an urgency to identify the true hosts responsible for transmission since human infections caused by this species of Rickettsia have been reported. For instance, $R$. asembonensis was identified in four patients displaying common febrile symptoms in Peru (Palacios-Salvatierra et al., 2018) and two human blood samples in Zambia (Moonga et al., 2021). Similarly, in Malaysia, the first report of this infection was in a 15-year-old boy presenting typical febrile symptoms however, with no signs of a tick bite (Kho et al., 2016). Interestingly, another case presented a co-infection with malaria in Sabah (Tay et al., 2019).

Our study has revealed the possibility of domestic animals (sheep and goat) as a potential host of rickettsial infections in Malaysia. The tropical climate of Malaysia creates a favourable environment for the proliferation of Rickettsia-infected ticks and fleas. An increased exposure to these vectors and its reservoirs, therefore, pose a zoonotic threat to the local population, especially animal handlers, and farm workers. This preliminary study has yet to establish the competency of the goat and sheep as reservoirs of this emerging pathogen however, the molecular evidence of rickettsioses in these samples introduces concern over the complexity of the host-reservoir system of this bacterium.

\section{Declarations}

\section{Availability of data and material}

The corresponding author declares that all information as regards this study is available online for public view.

\section{Code availability}

Not applicable.

\section{Author' contribution}

Conceived or designed study: VLL, TKT, SAB, PC, HNQN, MSFH, NHA, MNN, YAIL. Performed research: VLL, SSA, TKT, PB. Analyzed data: VLL, SSA, TKT, PB. Contributed new methods or models: SAB, PC, HNQN, MSFH, NHA, MNN, YAIL. Wrote the paper: VLL, SSA, TKT

\section{Funding}


This work was supported by funding from the Ministry of Higher Education, Malaysia, under the Higher Institution Centre of Excellence (HICoE) niche area vector and vector-borne diseases (MO002-2019).

\section{Statement of animal right}

This study was approved by the Department of Veterinary Services, Malaysia [Reference Number: JPV:BPI/100-1/12JLDIXXXX(15)]

\section{Consent to participate}

Not applicable.

\section{Consent for publication}

Permission to publish this paper was obtained from the Department of Veterinary Services, Malaysia

\section{Conflict of interest}

The authors declare that they have no conflict of interest.

\section{References}

1. Aung AK, Spelman DW, Murray RJ, Graves S (2014) Rickettsial infections in Southeast Asia: implications for local populace and febrile returned travelers. Am J Trop Med Hyg 91(3):451-460 https://doi.org/10.4269/ajtmh.14-0191

2. Edouard S, Bhengsri S, Dowell SF, Watt G, Parola P, Raoult D (2014) Two human cases of Rickettsia felis infection, Thailand. Emerg Infect Dis 20(10):1780-1781 https://doi.org/10.3201/eid2010.140905

3. Hall TA (1999) BioEdit: A User-Friendly Biological Sequence Alignment Editor and Analysis Program for Windows 95/98/NT. Nucleic Acids Symp Ser 41:95-98

4. Kho KL, Koh FX, Hasan LI, Wong LP, Kisomi MG, Bulgiba A, Nizam QN, Tay ST (2017) Rickettsial seropositivity in the indigenous community and animal farm workers, and vector surveillance in Peninsular Malaysia. Emerg Microbes Infect 6(4):e18. https://doi.org/10.1038/emi.2017.4

5. Kho KL, Koh FX, Singh HK, Zan HA, Kukreja A, Ponnampalavanar S, Tay ST (2016) Spotted fever group rickettsioses and murine typhus in a Malaysian teaching hospital. Am J Trop Med Hyg 95(4):765-768. https://doi.org/10.4269/ajtmh.16-0199

6. Kumar M, Singh R, Yadav M (2014) Indian tick typhus presenting with gangrene: A case report from an urban slum of Delhi. Indian J Pediatr 81(1):95-97. https://doi.org/10.1007/s12098-013-1095-7 
7. Labruna MB, Whitworth T, Horta MC, Bouyer DH, McBride JW, Pinter A, Popov V, Gennari SM, Walker DH (2004) Rickettsia species infecting Amblyomma cooperi ticks from an area in the state of São Paulo, Brazil, where Brazilian spotted fever is endemic. J Clin Microbiol 42(1):90-98 https://doi.org/10.1128/JCM.42.1.90-98.2004

8. Low VL, Prakash BK, Tan TK, Sofian-Azirun M, Anwar FHK, Vinnie-Siow WY, AbuBakar S (2017) Pathogens in ectoparasites from free-ranging animals: Infection with Rickettsia asembonensis in ticks, and a potentially new species of Dipylidium in fleas and lice. Vet Parasitol 245:102-105 https://doi.org/10.1016/j.vetpar.2017.08.015

9. Low VL, Tan TK, Khoo JJ, Lim FS, AbuBakar S (2020) An overview of rickettsiae in Southeast Asia: Vector-animal-human interface. Acta Trop. 202:105282 https://doi.org/10.1016/j.actatropica.2019.105282

10. Maina AN, Luce-Fedrow A, Omulo S, Hang J, Chan TC, Ade F, Jima DD, Ogola E, Ge H, Breiman RF, Njenga MK, Richards AL (2016) Isolation and characterization of a novel Rickettsia species (Rickettsia asembonensis sp. nov.) obtained from cat fleas (Ctenocephalides felis). Int J Syst Evol Microbiol 66(11):4512-4517 https://doi.org/10.1099/ijsem.0.001382

11. Mokhtar AS, Tay ST (2011). Molecular detection of Rickettsia felis, Bartonella henselae, and $B$. clarridgeiae in fleas from domestic dogs and cats in Malaysia. Am J Trop Med Hyg 85(5):931-933 https://doi.org/10.4269/ajtmh.2011.10-0634

12. Moonga LC, Hayashida K, Mulunda NR, Nakamura Y, Chipeta J, Moonga HB, Namangala B, Sugimoto C, Mtonga Z, Mutengo M, Yamagishi J (2021). Molecular detection and characterization of Rickettsia asembonensis in human blood, Zambia. Emerg Infect Dis 27(8):2237-2239. https://doi.org/10.3201/eid2708.203467

13. Palacios-Salvatierra R, Cáceres-Rey O, Vásquez-Domínguez A, Mosquera-Visaloth $P$, Anaya-Ramírez E (2018) Rickettsial species in human cases with non-specific acute febrile syndrome in Peru. Rev Peru Med Exp Salud Publica 35(4):630-635 https://doi.org/10.17843/rpmesp.2018.354.3646

14. Parola P, Miller RS, McDaniel P, Telford SR, Rolain JM, Wongsrichanalai C, Raoult D (2003) Emerging rickettsioses of the Thai-Myanmar border. Emerg Infect Dis 9(5):592-595 https://doi.org/10.3201/eid0905.020511

15. Parola P, Paddock CD, Raoult D (2005) Tick-borne rickettsioses around the world: emerging diseases challenging old concepts. Clin Microbiol Rev 18(4):719-756

16. Rohaya MA, Tuba Thabitah AT, Kasmah S, Azzura L, Chandrawathani P, Saipul BAR. 2017. Common blood parasites diagnosed in ruminants from 2011 to 2015 at the Central Veterinary Laboratory, Sepang, Malaysia. Malaysian J Vet Res 8(1):163-167

17. Tay ST, Kho KL, Vythilingam I, Ooi CH, Lau Y.L (2019) Investigation of possible rickettsial infection in patients with malaria. Trop Biomed 36(1):257-262

18. Tay ST, Koh FX, Kho KL, Sitam FT (2015) Rickettsial infections in monkeys, Malaysia. Emerg Infect Dis 21(3):545-547 https://doi.org/10.3201/eid2103.141457 
19. Weinert LA, Werren JH, Aebi A, Stone GN, Jiggins FM (2009) Evolution and diversity of Rickettsia bacteria. BMC Biol 7:6-6. https://doi.org/10.1186/1741-7007-7-6

\section{Figures}

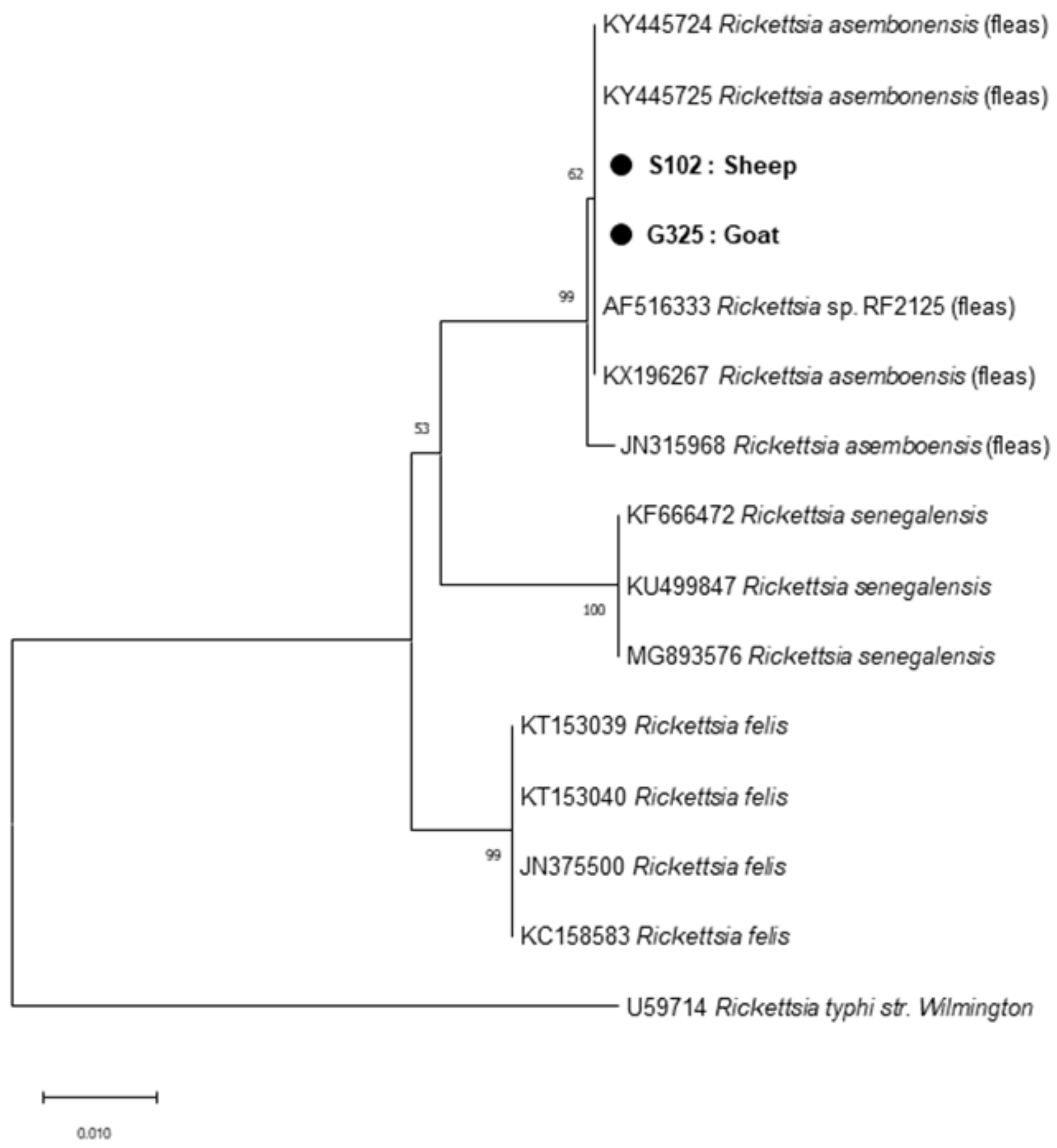

Figure 1

Dendogram depicting the phylogenetic position of Rickettsia detected from the goat (G325) and sheep (S102) sample with other published Rickettsia species (based on comparison of gltA gene sequences). 
The dendogram was constructed using the neighbor-joining method with Kimura's two parameter model of substitution (K2P distance). Rickettsia typhi (U59714) was used as an outgroup for comparison. 